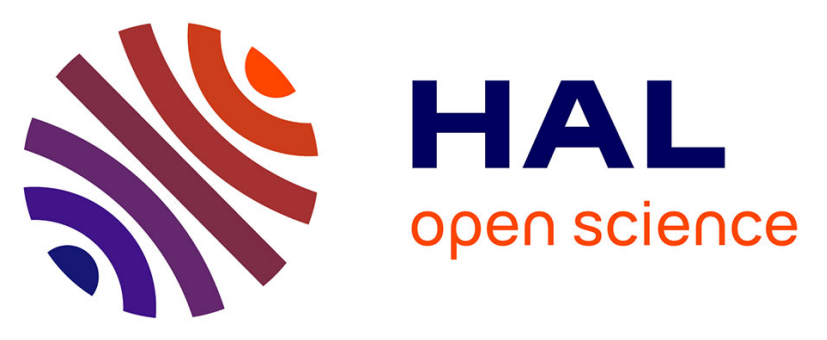

\title{
Uncatalyzed Formation of Polyaminoboranes from Diisopropylaminoborane and Primary Amines: a Kinetically Controlled Polymerization Reaction
}

Marc Devillard, Carlos Antonio de Albuquerque Pinheiro, Elsa Caytan, Claire Roiland, Chiara Dinoi, Iker Del rosal, Gilles Alcaraz

\section{To cite this version:}

Marc Devillard, Carlos Antonio de Albuquerque Pinheiro, Elsa Caytan, Claire Roiland, Chiara Dinoi, et al.. Uncatalyzed Formation of Polyaminoboranes from Diisopropylaminoborane and Primary Amines: a Kinetically Controlled Polymerization Reaction. Advanced Synthesis and Catalysis, 2021, 363 (9), pp.2417-2426. 10.1002/adsc.202001458 . hal-03127420

\author{
HAL Id: hal-03127420 \\ https://hal.science/hal-03127420
}

Submitted on 19 Feb 2021

HAL is a multi-disciplinary open access archive for the deposit and dissemination of scientific research documents, whether they are published or not. The documents may come from teaching and research institutions in France or abroad, or from public or private research centers.
L'archive ouverte pluridisciplinaire HAL, est destinée au dépôt et à la diffusion de documents scientifiques de niveau recherche, publiés ou non, émanant des établissements d'enseignement et de recherche français ou étrangers, des laboratoires publics ou privés. 


\title{
Uncatalyzed Formation of Polyaminoboranes from Diisopropylaminoborane and Primary Amines: a Kinetically Controlled Polymerization Reaction
}

\author{
Marc Devillard, ${ }^{\mathrm{a}}$ Carlos Antonio De Albuquerque Pinheiro, ${ }^{\mathrm{a}}$ Elsa Caytan, ${ }^{\mathrm{a}}$ Claire \\ Roiland, ${ }^{\mathrm{a}}$ Chiara Dinoi, ${ }^{\mathrm{b}}$ Iker Del Rosal, ${ }^{\mathrm{b}}$ and Gilles Alcaraz*a \\ a Univ Rennes, CNRS, ISCR (Institut des Sciences Chimiques de Rennes) - UMR 6226, F-35000 Rennes, France \\ phone: (+33) 223235188 \\ E-mail: gilles.alcaraz@univ-rennes1.fr \\ b LPCNO, CNRS \& INSA, Université de Toulouse, 135 avenue de Rangueil, 31077 Toulouse, France
}

Supporting information for this article is available on the WWW under http://dx.doi.org/10.1002/adsc.201\#\#\#\#\#\#.

\begin{abstract}
Recently, we disclosed the uncatalyzed formation of polyaminoboranes (PABs) from monomeric diisopropylaminoborane $\left({ }^{i} \mathrm{Pr}_{2} \mathrm{~N}-\mathrm{BH}_{2}\right)$ and primary amines $\left(\mathrm{RNH}_{2}\right)$. Their structure is studied through a detailed multinuclear NMR study and their full spectroscopic characterization is presented revealing that $\mathrm{N}$-alkyl substituted PABs exhibit magnetically non-equivalent methylenic protons in the close vicinity of the $\mathrm{BN}$-backbone. We also performed an in-depth theoretical study of this global chemical process. The mechanism is fully apprehended and the strong influence
\end{abstract}

of the temperature on the outcome of the reaction is unveiled. DFT-calculations clearly show that the formation of the polyaminoboranes $\left(\mathrm{RNH}-\mathrm{BH}_{2}\right)_{\mathrm{n}}$ results from a kinetically controlled step-growth polymerization reaction that can be globally viewed as a head-to-tail association process of the in situ generated transient monomeric monoalkylamino-borane [RNH-BH $\mathrm{RH}_{2}$.

Keywords: aminoboranes; BN compounds; boron; polymerization, Inorganic polymers

generally restricted to $\mathrm{N}$-alkyl substituents althoug improvements have been very recently achieved by Manners and co-workers with early transition metals complexes based on titanocene catalysts. ${ }^{[5]}$ Recently, metal-free routes have appeared as a promising alternative (Scheme 1B), ${ }^{[6]}$ providing a simple and straight-forward access to processable polyaminoboranes with high molecular masses.

A. Metal-catalyzed synthesis of PABs polyaminoboranes $\left(\mathrm{RHN}-\mathrm{BH}_{2}\right)_{\mathrm{n}} \quad(\mathrm{PABs})$ have attracted considerable attention over the past decade, strongly benefiting from the numerous studies on metal-catalysed dehydropolymerization of amineboranes with concomitant production of dihydrogen. ${ }^{[2]}$ With a $\mathrm{B}_{\mathrm{sp} 3} \mathrm{~N}_{\mathrm{sp} 3}$ backbone, polyaminoboranes are often presented as the inorganic analogues of the well-known polyolefins and show great potential as piezoelectric materials ${ }^{[3]}$ or as preceramic polymers for advanced $\mathrm{BN}$ materials. ${ }^{[4]}$ To date, this family of $\mathrm{BN}$ polymers remains relatively underdeveloped. While catalytic routes should offer interesting prospects for the efficient and tailored synthesis of polyaminoboranes (Scheme 1A), the polymerization process predominantly depends on the catalyst system. ${ }^{[2 a-1]}$ In terms of functionality, limitations are imposed by the compatibility between the catalyst, mostly based on late transition metals, and the nitrogen functional group of the amine-borane substrate. The scope is

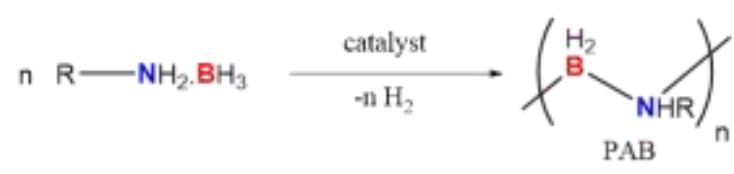

B. Metal-free synthesis of PABs

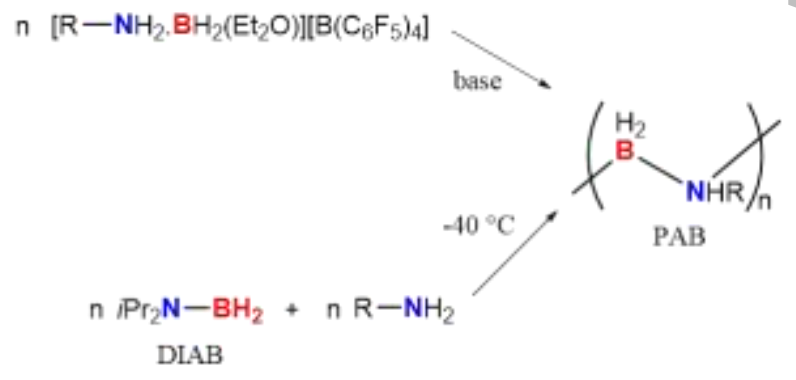

Scheme 1. Strategies toward polyaminoboranes synthesis. 
In this framework, we showed ${ }^{[6 b]}$ for the first time that a) polyaminoboranes could be efficiently produced with neither dihydrogen evolution nor salt formation by simple reaction of diisopropylaminoborane ${ }^{i} \mathrm{Pr}_{2} \mathrm{~N}-\mathrm{BH}_{2}$ (DIAB) with a primary amine $\mathrm{RNH}_{2}$, b) , the reaction tolerates olefinic functional groups enabling the design of polyaminoboranes containing $\mathrm{N}$-unsaturated sidechains, as shown by the isolation of polyallylaminoborane, and c) the reaction conditions and particularly the temperature plays a crucial role on the reaction outcome. This last statement is intimately linked to the reaction mechanism and, as in metal-catalysed routes, the generation and selfassociation of monomeric aminoborane units [RNH$\mathrm{BH}_{2}$ ], which is at the heart of the polymerization process, deserves a specific attention.

Following our recent results on this metal-free polymerization reaction, we have undertaken a more detailed study on the polymer characterization and on the reaction mechanism mostly based on the products previously observed and characterized.

\section{Results and Discussion}

We have recently reported a general procedure for the synthesis of polyaminoboranes (PABs) consisting in the addition of a primary amine to diisopropylaminoborane (DIAB) neat, at $-40^{\circ} \mathrm{C}$.

Performing the same reaction at room temperature led to a different reaction outcome with the formation of a mixture of boron containing species II-R-VI-R that have been unambiguously identified by multinuclear NMR spectroscopy when involving the $n$-butylamine species $(\mathrm{R}=\mathrm{Bu})($ Scheme 2$)$.

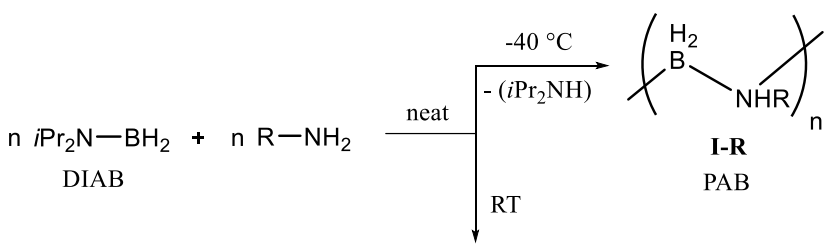

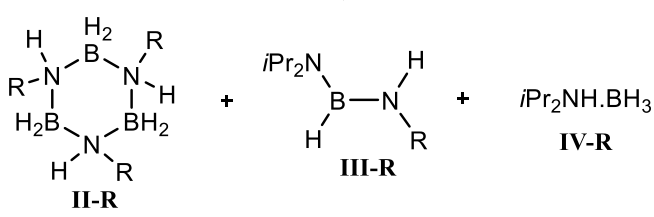

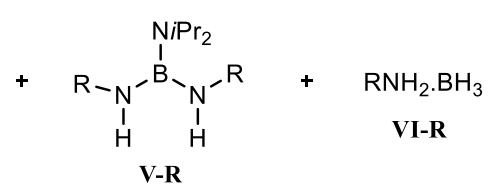

Scheme 2. Reaction of DIAB with primary amines at $40^{\circ} \mathrm{C}$ and at room temperature.

It is important to note that the reaction can be also conducted in solution, at low temperature, affording the corresponding PABs in similar yields to those obtained by the same reactions performed under neat conditions. ${ }^{[7]}$
Because of the extremely poor solubility in common organic solvents of prototypical PABs I-H and I-Me with which our study had begun, we erroneously considered that all PABs prepared thereafter would display a low solubility. This led us to spectroscopically characterize them by solid state ${ }^{13} \mathrm{C}\left\{{ }^{1} \mathrm{H}\right\}$ and in-solution ${ }^{11} \mathrm{~B}\left\{{ }^{1} \mathrm{H}\right\} \mathrm{NMR}^{[6 b]}$ at first, and later on by ${ }^{11} \mathrm{~B}\left\{{ }^{1} \mathrm{H}\right\}$ solid state NMR (SI-Figure S0). Further analyses were conducted and except for $\mathbf{I}-\mathbf{H}$ and I-Me, in-solution ${ }^{1} \mathrm{H},{ }^{13} \mathrm{C}\left\{{ }^{1} \mathrm{H}\right\}$ and ${ }^{1} \mathrm{H}-{ }^{13} \mathrm{C}$ HSQC spectra could be recorded for the prepared PABs (SIFigure S1-S21). Well-resolved spectra were obtained and PABs I-R $(\mathrm{R}=\mathrm{Et}, \mathrm{Pr}, \mathrm{Bu}, \mathrm{Et} / \mathrm{Bu}(1 / 1), \mathrm{Et} / \mathrm{Pr}$ (1/2), Allyl) were fully characterized. In the ${ }^{1} \mathrm{H}$ NMR, they all exhibit a broad singlet at $\delta 2.5-3.0 \mathrm{ppm}$ for the NH group (SI-Figure S1, S6, S10, S14, S17 and S18) in agreement with the NMR data reported so far for this family of polymer. ${ }^{[2 \mathrm{k}]}$

In the case of I-Allyl, the integrity of thallylaminoborane repeating unit was ascertained by selective 1D ${ }^{1} \mathrm{H}$-TOCSY experiments showing the correlation between vicinal hydrogens and even beyond for the $\mathrm{CH}$ protons (SI-Figure S22). More surprising is the signature of the alpha- and betamethylene groups of the $N$-substituent for the I-Et, IPr and I-Bu polymers (Figure 1 - See also SI-Figure S1, S6 and S10).

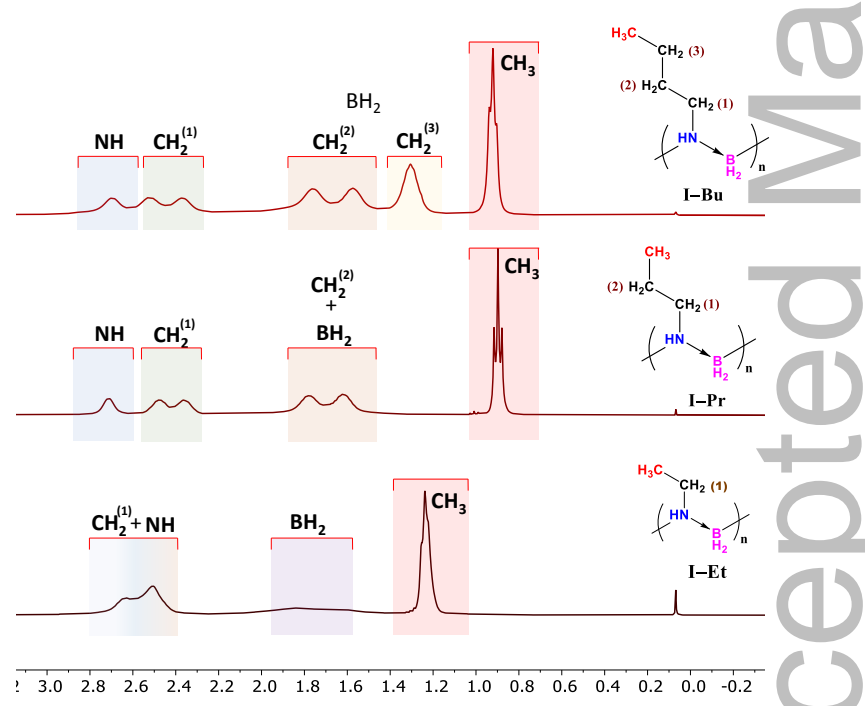

Figure 1. Enlarged ${ }^{1} \mathrm{H}$ NMR spectra of I-Et, I-Pr and I-Bu.

In the ${ }^{1} \mathrm{H}$ NMR spectra, each of these $\mathrm{CH}_{2}$ groups resonates as a set of two broad signals separated by 45 to $75 \mathrm{~Hz}$, presumably due to the non-equivalence of the two methylenic protons ${ }^{[8]}$ (Table 1).

Their connectivity to the same carbon atom has been unambiguously ascertained by the $2 \mathrm{D}{ }^{1} \mathrm{H}-{ }^{13} \mathrm{C}$ HSQC and ${ }^{1} \mathrm{H}-{ }^{1} \mathrm{H}$ COSY NMR experiments (SI-Figure $\mathrm{S} 4$, S5, S8, S9, S12 and S13). The magnetic nonequivalence of these geminal protons can only be detected in the close vicinity ( $\alpha$ - and $\beta$-methylenes) of the nitrogen and vanishes for the $\gamma$-methylene (IBu). 
Table 1. Chemical shifts of the protons of the methylene groups in I-Et, I-Pr and I-Bu.

\begin{tabular}{|c|c|c|c|}
\hline$\underbrace{\mathrm{B}_{2}}{ }_{\mathrm{NHR}}\}_{\mathrm{n}}$ & $\begin{array}{c}\delta(\mathrm{ppm}) \\
\mathrm{N}-\mathrm{C} \boldsymbol{H}_{2}\end{array}$ & $\begin{array}{c}\delta(\mathrm{ppm}) \\
\mathrm{N}-\mathrm{CH}_{2}-\mathrm{CH}_{2}\end{array}$ & $\begin{array}{c}\delta(\mathrm{ppm}) \\
\mathrm{N}-\mathrm{CH}_{2}-\mathrm{CH}_{2}- \\
\mathrm{CH}_{2}\end{array}$ \\
\hline I-Et & 2.50 and 2.63 & - & - \\
\hline I-Pr & 2.36 and 2.48 & 1.62 and 1.78 & - \\
\hline I-Bu & 2.37 and 2.52 & 1.57 and 1.76 & 1.31 \\
\hline
\end{tabular}

This feature could be linked to the rigidity of the $\mathrm{N}$ alkyl substituent that would get more important close to the $\mathrm{B}-\mathrm{N}$ backbone thus hindering the rotation around the $-\mathrm{CH}_{2}-\mathrm{CH}_{2}$ - bonds. Related to this, the ${ }^{1} \mathrm{H}-$ ${ }^{1} \mathrm{H}$ COSY NMR spectrum displays distinct correlations between pairs of vicinal methylenic protons within the alkyl chain due to the well-known dependence of the ${ }^{3} J_{\mathrm{HH}}$ coupling constant on the $\mathrm{HCCH}$ dihedral angle. ${ }^{[9]}$

The case of the $\mathrm{BH}_{2}$ group that is easily observable in the case of I-Et and I-Allyl is somewhat different. The $\mathrm{BH}_{2}$ gives a broad resonance signal integrating for $2 \mathrm{H}$ in the region $\delta 1.5$ to 2.0 $\mathrm{ppm}$. Upon ${ }^{11} \mathrm{~B}$ decoupling, this signal sharpens into two overlapping broad signals (Figure 2- See also SIFigure S2 and S19).

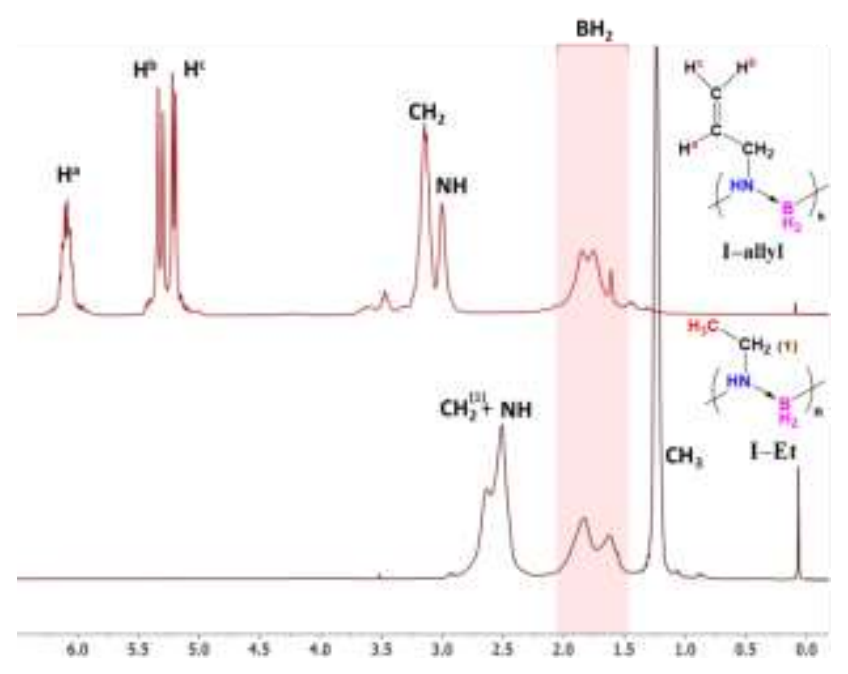

Figure 2. ${ }^{1} \mathrm{H}\left\{{ }^{11} \mathrm{~B}\right\}$ NMR spectra of I-Et (bottom) and IAllyl (top).

For I-Allyl, they are separated by $37 \mathrm{~Hz}$ at $\delta$ 1.83 and $1.73 \mathrm{ppm}$, respectively. In the case of I-Et, the peak separation is more pronounced with two overlapping broad signals separated by $88 \mathrm{~Hz}$ at $\delta$ 1.84 and $1.62 \mathrm{ppm}$, respectively. On this basis, the splitting pattern observed upon boron decoupling can't be rationalized by involving a scalar coupling of the $\mathrm{BH}_{2}$ hydrogens with the neighbouring $\mathrm{NH}$ protons. Indeed, the peak separation vastly exceeds the expected value for vicinal couplings, as measured for the $\mathrm{MeNH}_{2} \cdot \mathrm{BH}_{3}$ and $\mathrm{Me}_{2} \mathrm{NH} . \mathrm{BH}_{3}$ compounds that display similar $\mathrm{N}_{\mathrm{sp} 3} \mathrm{H}-\mathrm{B}_{\mathrm{sp} 3} \mathrm{H}$ linkage $\left({ }^{3} J_{\mathrm{BH}-\mathrm{NH}}=4.2\right.$ and $3.3 \mathrm{~Hz}$ ), respectively (see SI-Figure S23-S25). Concerning the possible involvement of geminal couplings within the H-B-H fragment, expected at $c a$. $10 \mathrm{~Hz},{ }^{[10]}$ the broadness of the observed signals precludes any accurate interpretation to validate this possibility. We envisioned that the tacticity of the PABs could be responsible for this peculiar $\mathrm{BH}_{2}$ NMR signature by analogy with the well resolved signals of methylene groups in previously described carbon-based polymers such as polymethylmethacrylate (PMMA) or polybutylmethacrylate (PBMA). ${ }^{[11]}$

For an ideal isotactic structure, the geminal $\mathrm{CH}_{2}$ protons are chemically inequivalent resulting in a $\mathrm{AB}$ system whereas they are isochronous in the welldefined syndiotactic structure, due to the local symmetry of the $-\mathrm{CH}_{2}-$ unit. For the atactic polymer where the two types of linkage are present, the ${ }^{1} \mathrm{H}$ NMR spectrum displays both patterns (Figure 3). ${ }^{[11 a]}$
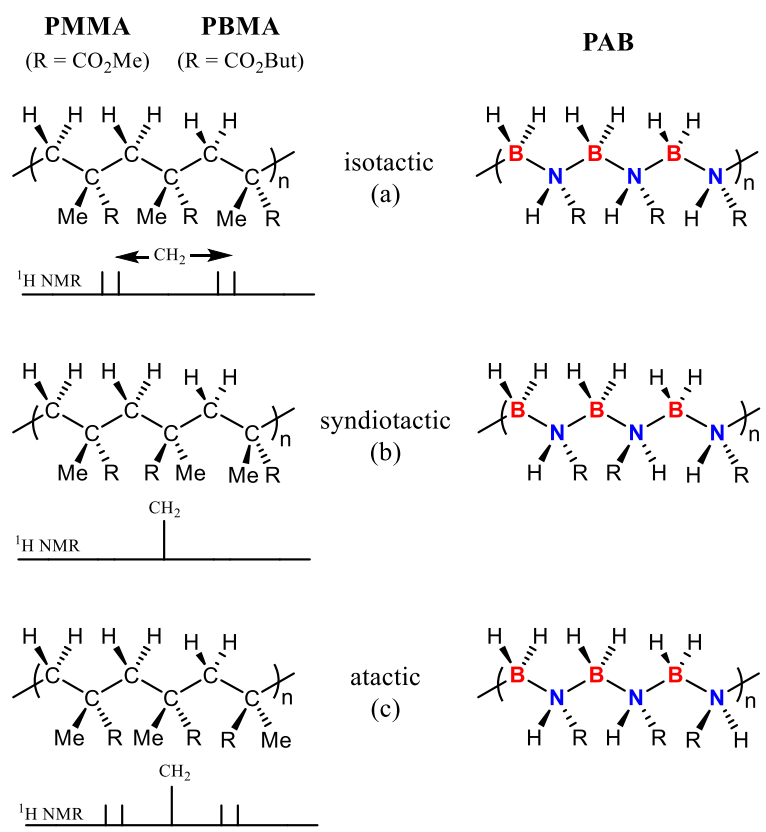

Figure 3. Illustration of the tacticity in PMMA, PBMA and $\mathrm{PAB}$.

Practically, the extensive overlap of many stereosequences $^{[12]}$ results in broadened signals for the methylenes moieties of many polymers.

In order to get more insight in the structure of thes $\mathrm{PAB}$ polymers and in the splitting patterns observed for the $\mathrm{BH}_{2}$ groups both in I-Allyl and I-Et, the synthesis of two new PABs that should display easy to observe $\mathrm{BH}_{2}$ groups was undertaken.

The I-Benz and I-TMSM polymers were analogously prepared in good yields from benzylamine and (trimethylsilyl)-methylamine, respectively. They display a $\mathrm{N}-\mathrm{CH}_{2}-\mathrm{Ph}$ and a $\mathrm{N}-$ $\mathrm{CH}_{2}-\mathrm{SiMe}_{3}$ chain that we thought NMR-silent in the region $\delta \quad 1.5$ to $2.0 \mathrm{ppm}$ allowing a better characterization of the $\mathrm{BH}_{2}$ resonance signal in the corresponding $\mathrm{PAB}$ polymer. 
Although perfectly characterised by multinuclear solid state NMR (SI-Figure S26-S27), their poor solubility prevented the recording of any significant spectrum precluding their characterization in solution. Further experimental evidence is still needed to definitively support the relationship between NMR signature and tacticity in the case of PABs. The results reported here emphasize the importance of the presence of alkyl chains for a good solubility in organic solvents. This particular point is illustrated with the additional syntheses of I-Myrt and I-Hex (scheme 3) performed in solution from (-)-cismyrtanylamine and hexylamine, respectively. I-Myrt and I-Hex have been characterized by multinuclear in-solution NMR (SI-Figures S28-S37).

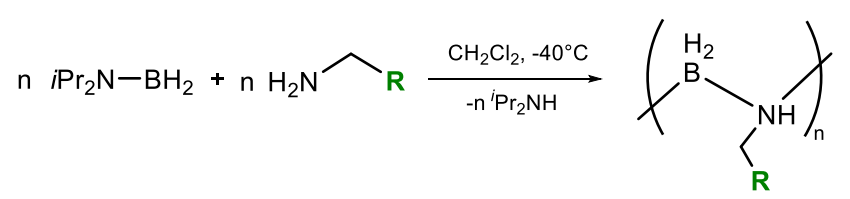
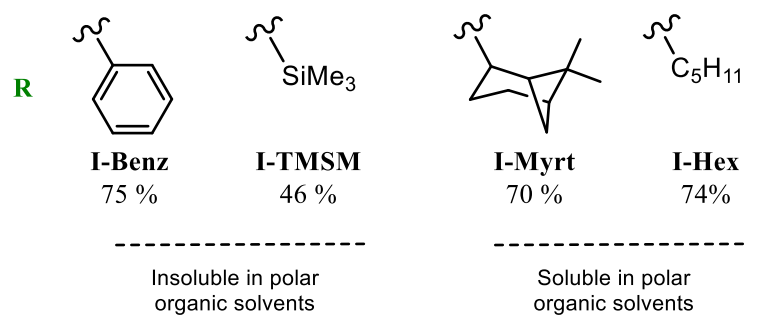

Scheme 3. Synthesis of I-Benz, I-TMSM, I-Myrt and IHex in dichloromethane at low temperature and influence of the N-substituent on the solubility of the PABs.

To go one step further, studies concerning the formation of PABs by amine-transfer reaction were undertaken. In order to validate the hypothesis of the transient formation of the amine-DIAB adduct followed by the elimination of diisopropylamine and the formation of the corresponding alkylaminoborane (Scheme 4), the stoichiometric reaction of DIAB with $n$-butylamine was performed in $d 8$-THF at $205 \mathrm{~K}$ and monitored by multinuclear NMR spectroscopy.

The ${ }^{11} \mathrm{~B}$ NMR spectrum shows the immediate and complete disappearance of DIAB at $\delta 37 \mathrm{ppm}$ and the presence of a broad signal at $\delta-7 \mathrm{ppm}$ in agreement with the presence of I-Bu. Traces of a compound at $\delta$ $-19.6 \mathrm{ppm}$ consistent with traces of an amine-borane adduct are also observed (SI-Figure S38). In the ${ }^{1} \mathrm{H}$ spectrum, I-Bu, recognisable by its peculiar spectroscopic signature, and diisopropylamine were both clearly identified as the major components of the reaction medium (SI-Figure S39). In the ${ }^{13} \mathrm{C}\left\{{ }^{1} \mathrm{H}\right\}$ and ${ }^{1} \mathrm{H}-{ }^{13} \mathrm{C}$ HSQC NMR spectra, traces of unreacted $n$ butylamine and IV could be identified by comparison of the data with authentic samples (SI-Figure S40S41), thus confirming the presence of an amineborane species previously detected by ${ }^{11} \mathrm{~B}$ NMR spectroscopy. The multinuclear NMR experiments performed at $205 \mathrm{~K}$ clearly showed that the formation of I-Bu takes place at very low temperature and contrarily to NHC-stabilized aminoboranes, ${ }^{[13]}$ neither the $n$-butylamine-DIAB adduct nor the monomeric butylaminoborane could be detected at this temperature.

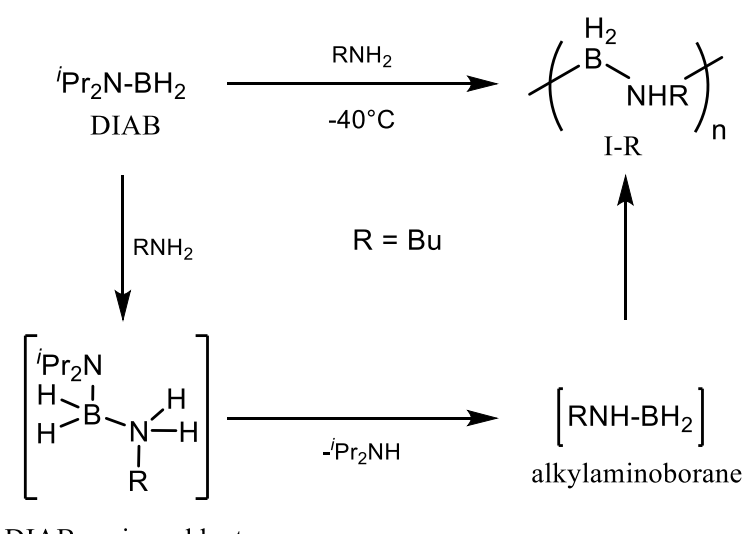

DIAB-amine adduct

Scheme 4. Suggested mechanism involving DIAB-amine adduct and alkylaminoborane intermediates.

In order to better understand the role of temperature and unveil the mechanism involved in the reaction, a DFT study was carried out at the DFTB3PW91 level of theory. In accordance with the experimental results at RT, the computed reaction of $n$-butylamine with DIAB, chosen as a model reaction, results mainly in a mixture of $\mathrm{B}_{\mathrm{sp} 2} \mathrm{H}-, \mathrm{B}_{\mathrm{sp} 3} \mathrm{H}_{2-}$ and $\mathrm{B}_{\mathrm{sp} 3} \mathrm{H}_{3}$-containing species (III-Bu-VI-Bu) with the cyclotriborazane compound (II-Bu) being the majc product (scheme 2). By changing the temperature, on the other hand, the outcome of the reaction $\mathrm{i}$ completely modified since a high mass polybutylaminoborane $\mathbf{I - B u}$ is formed as experimentally observed at $-40^{\circ} \mathrm{C}$ and below. ${ }^{[6 b]}$ The computed enthalpy profiles are shown in figures 4 6. ${ }^{[14]}$ Starting from the $n$-butylamine $\left(\mathrm{BuNH}_{2}\right)$ and DIAB $\left({ }^{i} \operatorname{Pr}_{2} \mathrm{NBH}_{2}\right)$, the first step involves the formation of the Lewis acid-base adduct $\mathbf{B}$ $\left(\mathrm{BuNH}_{2} \rightarrow \mathrm{BH}_{2}-\mathrm{N}^{i} \mathrm{Pr}_{2}\right)$ which was considered in analogy with the case previously reported for the NHCs ${ }^{[13]}$ Formation of adduct $\mathbf{B}$ takes place with almost no energy barrier in a slightly exothermic process $\left(-2.2 \mathrm{kcal}^{\mathrm{mol}}{ }^{-1}\right.$, Figure 4$)$.

From $\mathbf{B}$, the formation of the corresponding Lewis adduct $\mathbf{C}\left(\mathrm{BuNH}-\mathrm{BH}_{2} \leftarrow \mathrm{HN}^{i} \mathrm{Pr}_{2}\right)$ occurs through transition state TS-BC, displaying an activation barrier of $13.7 \mathrm{kcal}^{\mathrm{mol}}{ }^{-1}$. It involves an intramolecular N-to-N hydrogen shift from the $r$ butylamine moiety to the diisopropylamino group with $\mathbf{C}$ located at $-1.4 \mathrm{kcal}^{\mathrm{mol}}{ }^{-1}$. The dissociation of adduct $\mathbf{C}$ finalizing the amine-transfer reaction by the release of the diisopropylamine and the $\mathrm{BuNH}-\mathrm{BH}_{2}$ intermediate may then take place with almost no energy barrier via a weakly exothermic process $(\mathbf{D}$, $4.8 \mathrm{kcal}^{\mathrm{mol}}{ }^{-1}$, Figure 4).

As shown in Figure 4, an alternative hydrogen transfer route involving a bimolecular process from two molecules of $\mathbf{B}\left(\mathrm{Bu}-\mathrm{NH}_{2} \rightarrow \mathrm{H}_{2} \mathrm{~B}-\mathrm{N}^{i} \mathrm{Pr}_{2}\right)$ in $\mathbf{C 1}$ may also occur. 


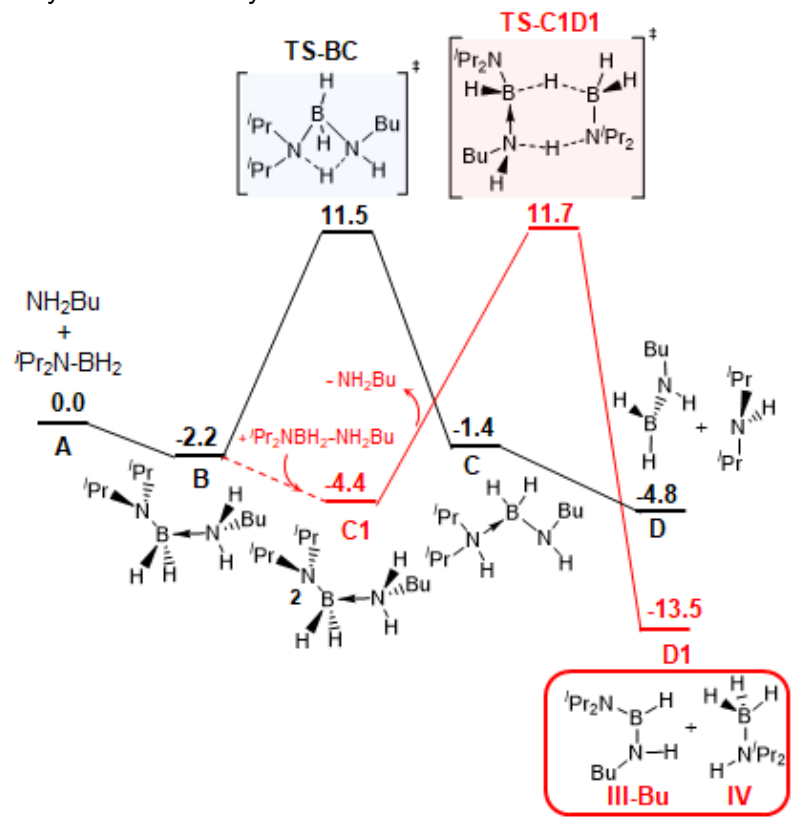

Figure 4. Enthalpy profiles of the reaction of $n$-butylamine and DIAB. Formation of the $\mathrm{BuNH}-\mathrm{BH}_{2}$ and ${ }^{i} \mathrm{Pr}_{2} \mathrm{NH}$ compounds (D) (black) together with III-Bu and IV (D1) (red).

After the release of the $n$-butylamine, the proton/hydride transfer operates through a sixmembered transition state TS-C1D1 with an energy barrier of $16.1 \mathrm{kcal}_{\mathrm{mol}}^{-1}$ with respect to $\mathbf{C 1}$. Interestingly, such hydrogen transfer between amineboranes and aminoboranes has been previously reported by Manners and co-workers. ${ }^{[15]}$ This reaction leading to D1 is exothermic by $-13.5 \mathrm{kcal}^{\mathrm{mol}} \mathrm{mo}^{-1}$ and results in the formation of the corresponding diaminoborane $\mathrm{BuNH}-\mathrm{B}(\mathrm{H})-\mathrm{N}^{i} \mathrm{Pr}_{2}$ (III-Bu) and ${ }^{i} \mathrm{Pr}_{2} \mathrm{NH}-\mathrm{BH}_{3}(\mathbf{I V})$ compounds.

When considering these two routes, it is important to note that the intermolecular process via TS-C1D1 is higher by $2.4 \mathrm{kcal}_{\mathrm{mol}}^{-1}$ than that of the intramolecular process through TS-BC. While both processes are accessible at room temperature and can operate simultaneously, the intramolecular process is less energy demanding and should be preferential at low temperature. Starting from D, three different scenarios that could rationalise the experimental results can be envisaged (Figure 5).

The first route is the trimerization of $n$ butylaminoborane into the cyclotriborazane species II-Bu through TS-E1F1. This route is highly exothermic (F1, -44.7 kcal.mol ${ }^{-1}$ ) and displays a high activation barrier (21.4 kcal.mol ${ }^{-1}$ with respect to E1). The second route involves a hydrogen transfer reaction between adduct $\mathbf{B}$ and the $n$ butylaminoborane $\left(\mathrm{BuNH}-\mathrm{BH}_{2}\right)$ compound in $\mathbf{D}$. This intermolecular process passes through TS-E2F2 leading to the formation of III-Bu and VI-Bu in F2 ($\left.22.0 \mathrm{kcal}^{\mathrm{mol}} \mathrm{mo}^{-1}\right)$. The reaction is therefore strongly exothermic (-15 kcal.mol ${ }^{-1}$ with respect to E2) only requiring a moderate activation barrier of 5.8

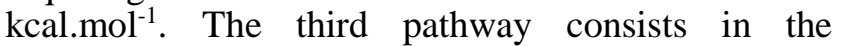
formation of the Lewis acid-base adduct $\mathbf{F}(\mathrm{Bu}-$ $\mathrm{NH}_{2} \rightarrow \mathrm{H}_{2} \mathrm{~B}-\mathrm{NHBu}$ ) from the $n$-butylaminoborane intermediate $\left(\mathrm{BuNH}-\mathrm{BH}_{2}\right)$ from $\mathbf{D}$ and the $n$ butylamine. The process passes through TS-EF and

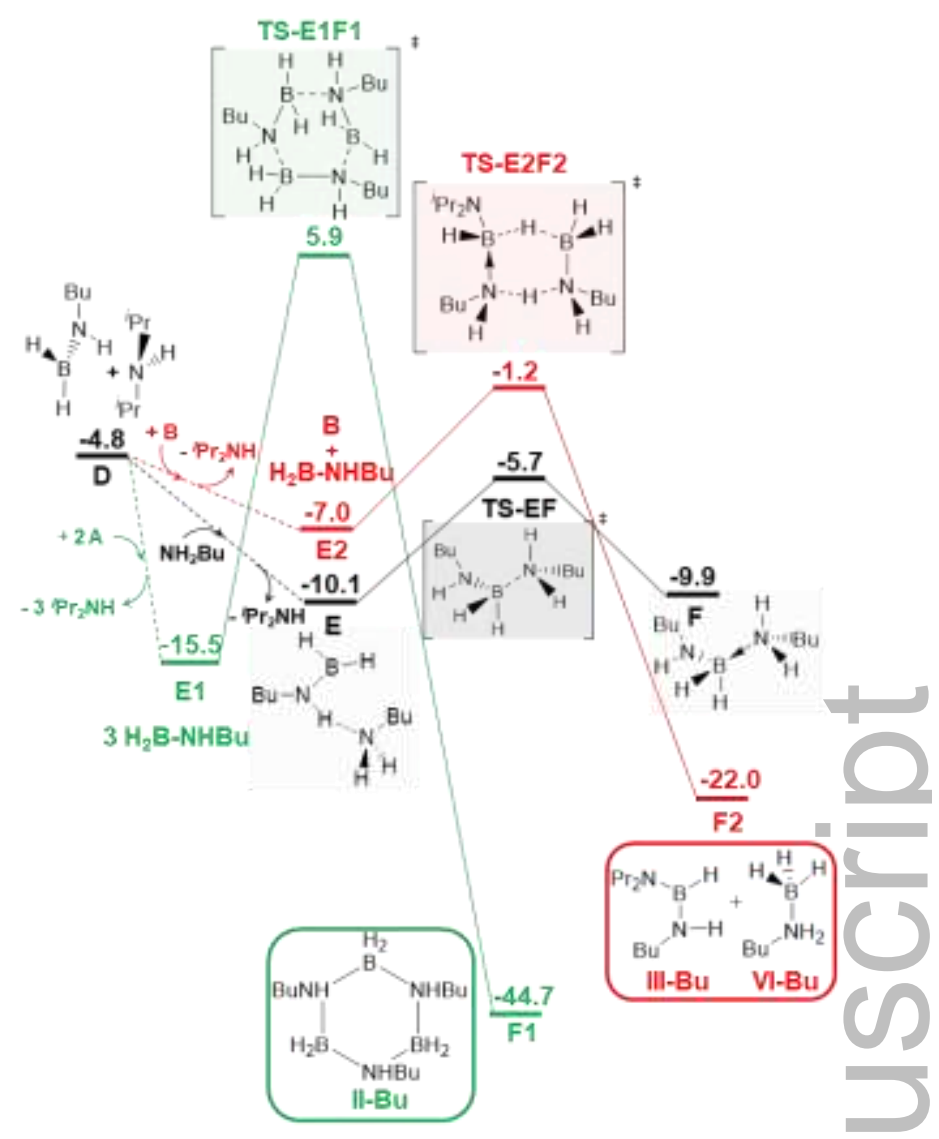

Figure 5. Enthalpy profile for the evolution of the BuNH$\mathrm{BH}_{2}$ species in $\mathbf{D}$ in the course of the reaction. Formation of adduct $\mathbf{F}$ (black) together with II-Bu (green), and IIIBu and VI-Bu (red).

results in a moderately exothermic reaction (-9.9 kcal.mol ${ }^{-1}$ ). It exhibits a low activation barrier (4. kcal.mol ${ }^{-1}$ with respect to $\mathbf{E}$ ) which is even lower by

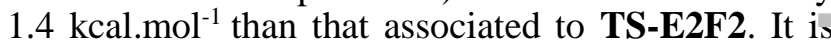
important to note that adduct $\mathbf{F}$ is thermodynamically and kinetically more stable than its analogue $\mathbf{C}$ (Figure 4). This can probably result from both the greater steric hindrance of diisopropylamine in $\mathbf{C}$ and the greater basicity of $n$-butylamine ${ }^{[16]}$ in $\mathbf{F}$, respectively weakening and strengthening the B-N bond in the corresponding adduct. Among these three routes, two of them are more particularly temperature dependent. Although the trimerisation barrier can be easily overcome at room temperature, to afford the cyclotriborazane compound II-Bu as the thermodynamic product of the reaction, the formation of the Lewis adduct $\mathbf{F}$ from $n$-butylamine and $n$ butylaminoborane $\left(\mathrm{BuNH}-\mathrm{BH}_{2}\right)$ remains kineticallv favoured at lower temperatures. In addition, the slower formation of the $n$-butylaminoborane $(\mathbf{D})$, at low temperature, probably makes the $n$-butylamine more widely available to react with the $n$ butylaminoborane intermediate $\left(\mathrm{BuNH}-\mathrm{BH}_{2}\right)$, as soon as it is formed, to give adduct $\mathbf{F}$.

The follow up of the reaction from species $\mathbf{F}$ is shown in Figure 6.

Once formed, adduct $\mathbf{F}$ can evolve along two distinct reactions, providing the products experimentally observed in the reaction medium. One possible pathway involves a proton/hydride transfer between 


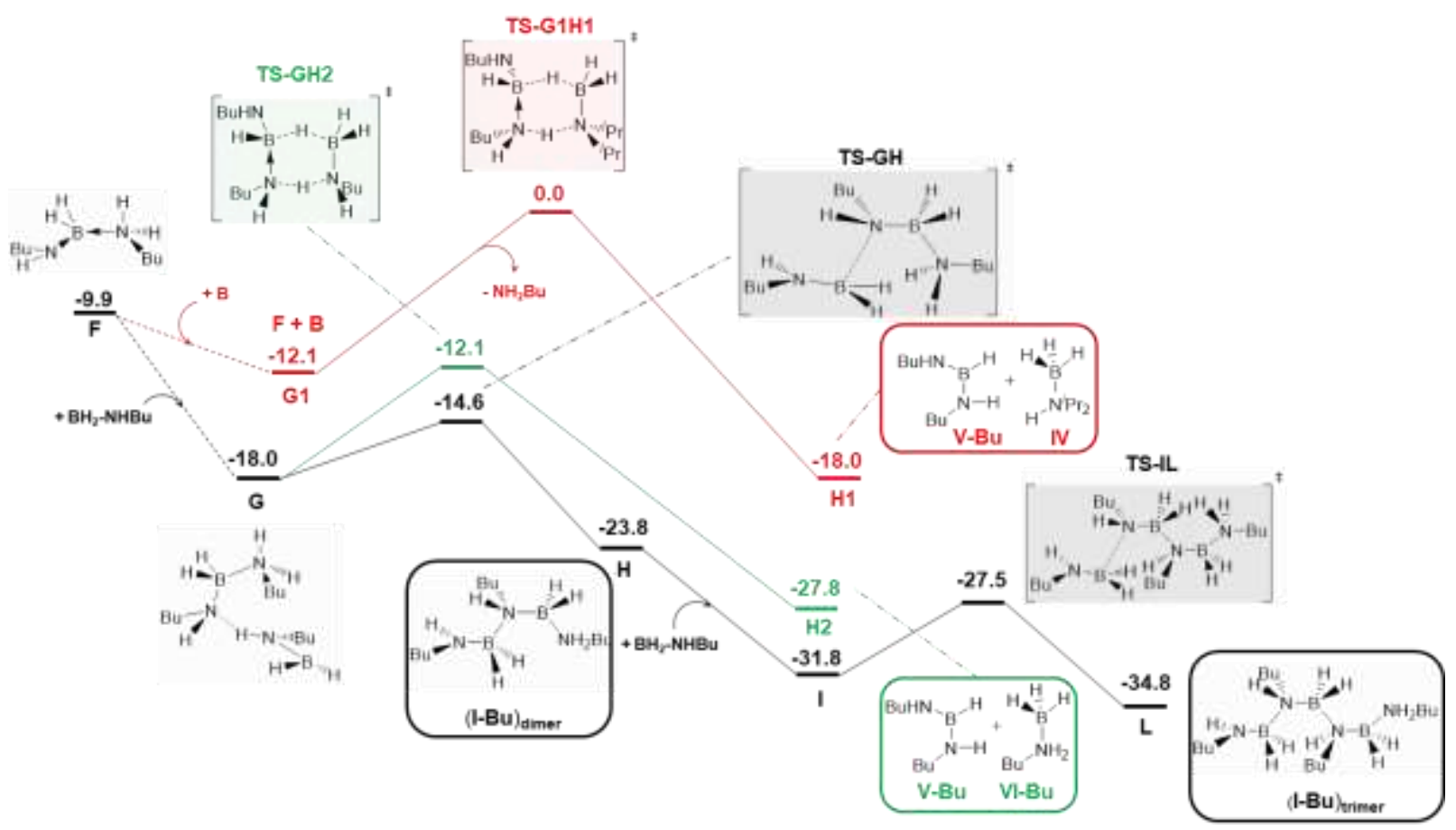

Figure 6. Enthalpy- profile for the evolution of $\mathbf{F}$ in the course of the reaction. Formation of the linear $\mathbf{I}-\mathbf{B} \mathbf{u}_{\text {dimer }}(\mathbf{H})$ and $\mathbf{I}-$ Butrimer (L) compounds (black) together with compounds IV, V-Bu and VI-Bu (green and red).

$\mathbf{F}$ and $\mathbf{B}$ through an energy demanding six-membered

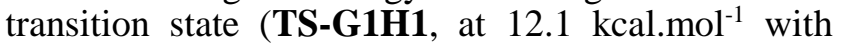
respect to $\mathbf{G 1}$ ), leading to the bis(butylamino)borane V-Bu and diisopropylamine-borane IV compounds at $-18.0 \mathrm{kcal} . \mathrm{mol}^{-1}$ (H1). In the second possible pathway, on the other hand, the reaction between $\mathbf{F}$ and the $n$ butylaminoborane intermediate $\left(\mathrm{BuNH}-\mathrm{BH}_{2}\right)$ evolves to two thermodynamically favourable issues involving either $i)$ the formation of bis(butylamino)borane $\mathbf{V}$-R along with $n$-butylamineborane IV (H2 at $-27.8 \mathrm{kcal}^{\mathrm{mol}} \mathrm{mol}^{-1}$ via a sixmembered proton/hydride transfer transition state TSGH2 or $i$ ) the formation of the linear dimer (I$\mathbf{B u})_{\text {dimer }}\left(\mathbf{H}\right.$ at $-23.8 \mathrm{kcal}^{\mathrm{mol}} \mathrm{mol}^{-1}$ ) through transition state TS-GH. Interestingly, the activation barrier corresponding to TS-GH2 (5.9 kcal.mol-1) is higher by $2.5 \mathrm{kcal}_{\mathrm{mol}} \mathrm{m}^{-1}$ than that of TS-GH $\left(3.4 \mathrm{kcal}^{\mathrm{mol}}{ }^{-1}\right)$ indicating that at low temperature, under kinetic control, the polymerization reaction is the predominant process. The dimer $(\mathbf{I}-\mathbf{B u})_{\text {dimer }}(\mathbf{H})$ may in turn react with one equivalent of $n$ butylaminoborane $\left(\mathrm{BuNH}-\mathrm{BH}_{2}\right)$ to provide the corresponding trimer $(\mathbf{I}-\mathbf{B u})_{\text {trimer }}\left(\mathbf{L},-34.8 \mathrm{kcal}_{\text {.mol }}{ }^{-1}\right)$ through an accessible activation barrier of 4.3

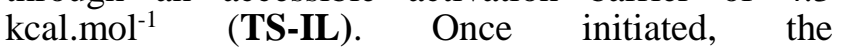
polymerization process can carry on, the lack of solubility of the growing polymer eventually acting as an additional driving force. From a global point of view, the profiles in Figures 4-6 indicate that the cyclotriborazane II-Bu and polybutylaminoborane IBu compounds represent the thermodynamic and kinetic products, respectively.

While the formation of II-Bu is a highly exothermic process $\left(-44.7 \mathrm{kcal}^{\mathrm{mol}} \mathrm{m}^{-1}\right)$, passing through a high energy-demanding transition state (TS-E1F1, 21.5 kcal.mol ${ }^{-1}$ ), the formation of the corresponding linear trimer (I-Bu) trimer in $\mathbf{L}$ displays a smaller exothermicity $\left(-34.8 \mathrm{kcal}^{\mathrm{mol}} \mathrm{m}^{-1}\right)$ involving much lower barrier steps. The highest activation barrier fo. the whole polymerization process from the starting DIAB and $n$-butylamine (A) compounds to th product $\mathbf{L}$ is indeed of $13.7 \mathrm{kcal}^{-\mathrm{mol}^{-1}}$ and corresponds to the intramolecular $\mathrm{N}$-to-N hydrogen shift in TS-BC.

In accordance with the experimental results, while at room temperature the cycloborazane compound is the major isolated product together with smaller amounts of III-Bu, IV, V-Bu and VI-Bu, at low temperature the polybutylaminoborane I-Bu polymer is selectively formed.

\section{Conclusion}

We recently disclosed a solventless uncatalyzed synthesis of PABs (I) from diisopropylaminoborane $\left({ }^{i} \mathrm{Pr}_{2} \mathrm{~N}-\mathrm{BH}_{2}\right)$ and primary amines $\left(\mathrm{RNH}_{2}\right)$ and evidenced that temperature plays a determining role on the outcome of the reaction: while PABs $\mathbf{I}$ are produced in good yield at low temperature, at room temperature the same experiment leads to cyclotriborazane II as the main compound with diaminoboranes (III and V) and amine-boranes (IV and VI) to a lesser extent. Interestingly, we described here a complete solution NMR study of the previously synthesized PABs. Despite initial solubility issues, we realized that the PABs polymers and copolymers, produced from primary $n$ alkylamines with hydrocarbon chains ranging beyond 
2 carbon atoms, are indeed soluble enough for insolution NMR studies.

Multinuclear NMR studies revealed that the protons of the alpha- and beta-methylene groups of the alkyl moiety in N-substituted PABs are magnetically nonequivalent. This can be rationalized by the hindered rotation around the $-\mathrm{C}^{\alpha} \mathrm{H}_{2}-\mathrm{C}^{\beta} \mathrm{H}_{2}$ - bonds of the alkyl chains, thus resulting in preferential conformations of these alkyl chains within the polymer.

Additionally, the $\mathrm{BH}_{2}$ groups present a peculiar spectroscopic signature that clearly raises the question of the tacticity in PABs. In order to tackle this point, still unknown for the best of our knowledge, we prepared model-PABs from benzylamine and (trimethylsilyl)methylamine with the hope to obtain a more readable ${ }^{1} \mathrm{H}$ NMR spectrum. Here again we faced with solubility issues, preventing the proper characterization of these PABs polymers in solution. The question of tacticity in PABs remains therefore open and investigations in this context are currently underway in our laboratory.

Theoretical calculations were carried out at the DFT level of theory, enabling the comprehension of the role of the temperature in the PABs synthetic process and the rationalization of the formation of the species experimentally observed at room temperature. The mechanism we propose from this in-depth theoretical study reveals that the formation of PABS is a kinetically controlled process starting, as previously postulated, by the initial formation of an amine-DIAB Lewis acid-base adduct which affords the $n$-alkylaminoborane $\left(\mathrm{RNH}^{\left.-\mathrm{BH}_{2}\right)}\right.$ key intermediate via an intramolecular N-to-N proton exchange. The resulting polymerization process involves the successive formation of Lewis acid-base adducts. Each incoming key $n$-alkylaminoborane monomer generates a new dative $\mathrm{B}-\mathrm{N}$ bond between its $\mathrm{BH}_{2}$ group and the amino moiety of the chain-end $n$ alkylaminoborane group of the growing polymer, ensuring the propagation of the polymeric chain. At a more elevated temperature, the trimerizaton of the $n$ alkylaminoborane into cyclotriborazane is the thermodynamically favored process. According to the computational study, the experimentally observed formation of amine-boranes and diaminoboranes mainly results from the bimolecular $\mathrm{NH}$ proton/BH hydride transfer through 6-membered transitions states.

\section{Experimental Section}

PABs I-H, I-Me, I-Et, I-Pr, I-Bu, I-Allyl, I-Et/Bu (1/1), and I-Et/Pr (1/2) were prepared as previously reported. ${ }^{.66]}$,

Synthesis of I-Benz: To a $-40{ }^{\circ} \mathrm{C}$ solution of $N, N$ diisopropylaminoborane $(2.17 \mathrm{~mL}, 1.52 \mathrm{~g}, 13.4 \mathrm{mmol})$ in dichloromethane $(10 \mathrm{~mL})$ was added a $-40{ }^{\circ} \mathrm{C}$ cooled solution of benzylamine $(1.50 \mathrm{~mL}, 1.44 \mathrm{~g}, 13.4 \mathrm{mmol}, 1$ eq.) in dichloromethane $(10 \mathrm{~mL})$ dropwise over 15 minutes and the resulting solution was allowed to warm up slowly to $0{ }^{\circ} \mathrm{C}$ in the cold bath. At this stage the cold bath was removed and the reaction mixture allowed warming up to room temperature. Volatiles were removed under vacuum giving a transparent residue that was then washed with acetonitrile (4 times $30 \mathrm{~mL}$ ). The resulting white powder was then dried under vacuum $(1.2 \mathrm{~g}, 75 \%)$. I-Benz was characterized by solid-state ${ }^{11} \mathrm{~B}\left\{{ }^{1} \mathrm{H}\right\}$ MAS NMR spectroscopy (see SI-Figure S26). $\delta_{\text {iso }}\left({ }^{1} \mathrm{~B}\right)=-7.7 \mathrm{ppm}-$ $\mathrm{C}_{\mathrm{Q}}=1.3 \mathrm{~Hz}-\eta_{\mathrm{Q}}=0.9$.

Synthesis of I-TMSM: To a $-40{ }^{\circ} \mathrm{C}$ solution of $\mathrm{N}, \mathrm{N}$ diisopropylaminoborane $(1.67 \mathrm{~mL}, 1.17 \mathrm{~g}, 10.4 \mathrm{mmol})$ in dichloromethane $(10 \mathrm{~mL})$ was added $\mathrm{a}-40{ }^{\circ} \mathrm{C}$ cooled solution of (aminomethyl)trimethylsilane $(1.50 \mathrm{~mL}, 1.07 \mathrm{~g}$, $10.4 \mathrm{mmol}, 1 \mathrm{eq}$.$) in dichloromethane (10 \mathrm{~mL})$ dropwise over 15 minutes and the resulting solution was allowed to warm up slowly to $0{ }^{\circ} \mathrm{C}$ in the cold bath. At this stage the cold bath was removed and the reaction mixture allowed warming up to room temperature. Volatiles were removed under vacuum giving a transparent residue that was suspended in acetonitrile $(30 \mathrm{~mL})$ and transferred on a filter frit. It was then washed 3 more times with acetonitrile giving a white powder that was dried under vacuum $(0.55$ $\mathrm{g}, 46 \%)$. I-TMSM was characterized by solid-state ${ }^{11} \mathrm{~B}\left\{{ }^{1} \mathrm{H}\right\}$ and ${ }^{29} \mathrm{Si}$ MAS NMR spectroscopy (see SI-Figure $\mathrm{S} 26-27) . \delta_{\text {iso }}\left({ }^{11} \mathrm{~B}\right)=-6.25 \mathrm{ppm}-\mathrm{C}_{\mathrm{Q}}=0.6 \mathrm{~Hz}-\eta_{\mathrm{Q}}=0.95$ $\delta\left({ }^{29} \mathrm{Si}\right)=45.2 \mathrm{ppm}$.

Synthesis of I-Myrt: A $-40{ }^{\circ} \mathrm{C}$ cooled solution of (-)-cismyrtanylamine (3.12 mL, $2.85 \mathrm{~g}, 18.6 \mathrm{mmol}, 1$ eq.) in dichloromethane $(10 \mathrm{~mL})$ was added dropwise over 15 minutes to a $-40{ }^{\circ} \mathrm{C}$ cooled solution of $N, N$ diisopropylaminoborane $(3.0 \mathrm{~mL}, 2.1 \mathrm{~g}, 18.6 \mathrm{mmol})$ in dichloromethane $(10 \mathrm{~mL})$ and the resulting solution was allowed to slowly warm up to room temperature in the cold bath over 10 hours giving a white precipitate and a colourless solution. Volatiles were removed under vacuum giving a transparent residue that was then washed with acetonitrile (3 times $20 \mathrm{~mL}$ ) and methanol (3 times $20 \mathrm{~mL}$ ). The resulting white powder was then dried under vacuum (70 \%). I-Myrt was characterized by solution NMR spectroscopy (see SI Figures S28-33). ${ }^{\mathrm{l}} \mathrm{H}$ NMR $\left(\mathrm{CDCl}_{3}\right.$, $500 \mathrm{MHz}): \delta=0.86-0.99(\mathrm{~m}, 1 \mathrm{H}, \mathrm{CHH}), 1.02(\mathrm{~m}, 3 \mathrm{H}$, $\left.\mathrm{CH}_{3}\right), 1.22\left(\mathrm{~m}, 3 \mathrm{H}, \mathrm{CH}_{3}\right), 1.31-1.52(\mathrm{~m}, 1 \mathrm{H}, \mathrm{CH} \mathrm{H}), 1.66$ 2.19 (m, 7H, $\left.3 \mathrm{CH}+\mathrm{CH}_{2}+\mathrm{BH}_{2}\right), 2.34-2.47$ (br., $1 \mathrm{H}, \mathrm{CH} H$ ), 2.47-2.70 (br., 3H, N-CH $H_{2} \mathrm{CH} H$ ), 2.75 (br., $1 \mathrm{H}, \mathrm{NH}$ ) ${ }^{11} \mathrm{~B}\left\{{ }^{1} \mathrm{H}\right\}\left(\mathrm{CDCl}_{3}, 128 \mathrm{MHz}\right): \delta=-5.2$ (br.); ${ }^{13} \mathrm{C}\left\{{ }^{1} \mathrm{H}\right\} \mathrm{NMl}$ $\left(\mathrm{CDCl}_{3}, 126 \mathrm{MHz}\right) \delta=19.5-20.4\left(\mathrm{~m}, \underset{\mathrm{C}}{\mathrm{C}} \mathrm{H}_{2}\right), 23.0-23.6(\mathrm{~m}$, $\left.\mathrm{CH}_{3}\right), 25.7-26.4\left(\mathrm{~m}, \mathrm{C} \mathrm{H}_{2}\right), 27.8-28.3\left(\mathrm{~m}, \mathrm{C} \mathrm{H}_{3}\right), 33.0-33.7$ $\left(\mathrm{m}, \underline{C} \mathrm{H}_{2}\right), 37.6(\mathrm{~s}, \underline{C} \overline{\mathrm{H}}), 38.6-38.9\left(\mathrm{~m}, \underline{C}^{\mathrm{lv}}\right), 41.1-41.7(\mathrm{~m}$, $\underline{C} \mathrm{H}), 43.4-43.8(\mathrm{~m}, \underline{C} \mathrm{H}), 58.5-58.7\left(\mathrm{~m}, \overline{\mathrm{N}}-\underline{C} \mathrm{H}_{2}\right)$.

Synthesis of I-Hex: A $-40{ }^{\circ} \mathrm{C}$ cooled solution of $\mathrm{n}$ hexylamine (2.77 mL, $2.122 \mathrm{~g}, 20.97 \mathrm{mmol}, 1$ eq.) in dichloromethane $(10 \mathrm{~mL})$ was added dropwise over 15 minutes to a $-40{ }^{\circ} \mathrm{C}$ cooled solution of $N, N-$ diisopropylaminoborane $(3 \mathrm{~mL}, 2.37 \mathrm{~g}, 20.97 \mathrm{mmol})$ in dichloromethane $(10 \mathrm{~mL})$ and the resulting transparent colourless solution was allowed to slowly warm up to $0^{\circ} \mathrm{C}$. The cold bath was removed and once the solution at room temperature, the volatiles were removed under vacuum leading to a white gummy solid that was then washed with acetonitrile $(3 \times 20 \mathrm{~mL})$ and methanol $(3 \times 20 \mathrm{~mL})$. The resulting white gummy powder was then dried under vacuum and I-hex was isolated in $74 \%$ yield $(1.76 \mathrm{~g})$. (see SI Figures S34-S37). ${ }^{1} \mathrm{H}$ NMR $\left(\mathrm{CDCl}_{3}, 400.16 \mathrm{MHz}\right): \delta=$ 0.88 (br s, $\left.3 \mathrm{H}, \mathrm{CH}_{3}\right), 1.29$ (br. s, $\left.6 \mathrm{H}, \mathrm{CH}_{3}-\left(\mathrm{CH}_{2}\right)_{3}-\right), 1.60$ and 1.77 (br., $2 \mathrm{H}, \mathrm{NCH}_{2}-\mathrm{CH}_{2}$ ), 2.36 and 2.50 (br., $2 \mathrm{H}$, $\left.\mathrm{NCH}_{2}-\mathrm{CH}_{2}\right), 2.68(\mathrm{br}, 1 \mathrm{H}, \mathrm{NH}) ;{ }^{11} \mathrm{~B}\left\{{ }^{1} \mathrm{H}\right\}\left(\mathrm{CDCl}_{3}, 128.38\right.$ $\mathrm{MHz}): \delta=-6.8$ (br.); ${ }^{13} \mathrm{C}\left\{{ }^{1} \mathrm{H}\right\}$ NMR $\left(\mathrm{CDCl}_{3}, 120.62 \mathrm{MHz}\right)$ $\delta=14.14\left(\mathrm{~s}, \underline{C} \mathrm{H}_{3}\right), 22.74\left(\mathrm{~s}, \mathrm{CH}_{3}-\mathrm{CH}_{2}\right), 27.33\left(\mathrm{~s}, \mathrm{CH}_{3}\right.$ $\left.\mathrm{CH}_{2}-\mathrm{CH}_{2}-\mathrm{CH}_{2}\right), 28.05\left(\mathrm{~s}, \mathrm{NCH}_{2}-\mathrm{CH}_{2}\right), 31.81\left(\mathrm{~s}, \mathrm{CH}_{3}-\mathrm{CH}_{2}-\right.$ $\left.\underline{C} \mathrm{H}_{2}\right), 51.14\left(\mathrm{~s}, \mathrm{~N}^{\mathrm{C}} \mathrm{H}_{2}\right)$.

\section{Acknowledgements}

We thank the C.N.R.S. and the University of Rennes 1. C.A.D.A.P. thanks the Brazilian Ministry of Education and the CAPES for his fellowship. G.A. and M.D. thank the Region Bretagne for its financial support (SAD-2 $\left.n^{\circ} 17048\right)$. This work was performed using HPC resources from CALMIP (Grant 2017-[p17010]) 


\section{References}

[1] a) A. M. Priegert, B. W. Rawe, S. C. Serin, D. P. Gates, Chem. Soc. Rev. 2016, 45, 922-953; b) O. Ayhan, T. Eckert, F. A. Plamper, H. Helten, Angew. Chem. Int. Ed. 2016, 55, 13321-13325; c) T. Lorenz, M. Crumbach, T. Eckert, A. Lik, H. Helten, Angew. Chem. Int. Ed. 2017, 56, 2780-2784.

[2] a) A. Rossin, M. Peruzzini, Chem. Rev. 2016, 116, 8848-8872; b) A. Staubitz, M. E. Sloan, A. P. M. Robertson, A. Friedrich, S. Schneider, P. J. Gates, J. Schmedt auf der Günne, I. Manners, J. Am. Chem. Soc. 2010, 132, 13332-13345; c) J. R. Vance, A. P. M. Robertson, K. Lee, I. Manners, Chem. Eur. J. 2011, 17, 4099-4103; d) M. Jeun, S. Park, G. H. Jang, K. H. Lee, ACS Appl. Mater. Interfaces 2014, 6, 16487-16492; e) C. Lichtenberg, M. Adelhardt, T. L. Gianetti, K. Meyer, B. de Bruin, H. Grützmacher, ACS Catalysis 2015, 5, 6230-6240; f) N. T. Coles, M. F. Mahon, R. L. Webster, Organometallics 2017, 36, 2262-2268; g) F. Anke, D. Han, M. Klahn, A. Spannenberg, T. Beweries, Dalton Trans. 2017, 46, 6843-6847; h) G. M. Adams, A. L. Colebatch, J. T. Skornia, A. I. McKay, H. C. Johnson, G. C. Lloyd Jones, S. A. Macgregor, N. A. Beattie, A. S. Weller, J. Am. Chem. Soc. 2018, 140, 1481-1495; i) A. L. Colebatch, B. W. Hawkey Gilder, G. R. Whittell, N. L. Oldroyd, I. Manners, A. S. Weller, Chem. Eur. J. 2018, 24, 5450-5455; j) M. Trose, M. Reiss, F. Reiss, F. Anke, A. Spannenberg, S. Boye, A. Lederer, P. Arndt, T. Beweries, Dalton Trans. 2018, 47, 12858-12862; k) D. A. Resendiz-Lara, G. R. Whittell, E. M. Leitao, I. Manners, Macromolecules 2019, 52, 7052-7064; 1) D. E. Ryan, K. A. Andrea, J. J. Race, T. M. Boyd, G. C. Lloyd-Jones, A. S. Weller, ACS Catalysis 2020, 10, 7443-7448; m) A. L. Colebatch, A. S. Weller, Chem. Eur. J. 2019, 25, 1379-1390.

[3] a) S. M. Nakhmanson, M. B. Nardelli, J. Bernholc, Phys Rev Lett 2004, 92, 115504; b) Y. Zhang, M. A. Hopkins, D. J. Liptrot, H. Khanbareh, P. Groen, X. Zhou, D. Zhang, Y. Bao, K. Zhou, C. R. Bowen, D. R. Carbery, Angew. Chem. Int. Ed. 2020, 59, 7808-7812.

[4]a) A. Staubitz, A. Presa Soto, I. Manners, Angew. Chem. Int. Ed. 2008, 47, 6212-6215; b) V. A. Du, T. Jurca, G. R. Whittell, I. Manners, Dalton Trans. 2016, 45, 10551062; c) X. Wang, T. N. Hooper, A. Kumar, I. K. Priest, Y. Sheng, T. O. M. Samuels, S. Wang, A. W. Robertson, M. Pacios, H. Bhaskaran, A. S. Weller, J. H. Warner, CrystEngComm 2017, 19, 285-294.

[5] E. A. LaPierre, B. O. Patrick, I. Manners, J. Am. Chem. Soc. 2019, 141, 20009-20015.

[6] a) O. J. Metters, A. M. Chapman, A. P. M. Robertson, C. H. Woodall, P. J. Gates, D. F. Wass, I. Manners, Chem. Commun. 2014, 50, 12146-12149; b) C. A. De Albuquerque Pinheiro, C. Roiland, P. Jehan, G. Alcaraz, Angew. Chem. Int. Ed. 2018, 57, 1519-1522.

[7] The polymerization is instantaneous. The presence of the solvent such as dichloromethane does not alter the course of the reaction but helps to maintain a correct stirring when gelation of the solution occurs under neat conditions. .

[8] The NMR profiles obtained by Manners et al. in the case of the iridium catalyzed dehydropolymerization of amine-boranes (ref 3b) suggest that this phenomenon could be also present although difficult to observe in the reported cases due to the presence of the alkyl chains used that render the ${ }^{1} \mathrm{H}$ spectra interest area less easily analysable.

[9] R. R. Fraser, R. N. Renaud, J. K. Saunders, Y. Y. Wigfield, Can. J. Chem. 1973, 51, 2433-2437.

[10] a) R. E. Mesmer, W. L. Jolly, J. Am. Chem. Soc. 1962, 84, 2039-2042; b) D. F. Gaines, R. Schaeffer, F. Tebbe, J. Phys. Chem. 1963, 67, 1937-1938; c) V. F. Bystrov, Russ. Chem. Rev. 1972, 41, 281-304; d) T. C. Farrar, G. R. Quinting, Inorg. Chem. 1985, 24, 1941-1943.

[11] a) A. J. White, F. E. Filisko, J. Polym. Sci.Polym. Lett. Ed. 1982, 20, 525-529; b) G. R. Quinting, R. Cai, Macromolecules 1994, 27, 6301-6306.

[12] P. A. Mirau, 1993. NMR characterisation of polymers. In: Polymer Characterisation, 1st ed. (Eds.. B.J. Hunt, M.I. James), Springer, Dordrecht, pp. 37-68.

[13] N. E. Stubbs, T. Jurca, E. M. Leitao, C. H. Woodall, I. Manners, Chem. Commun. 2013, 49, 9098-9100.

[14] To overcome the error related to the DFT calculation of the entropic terms, especially in the presence of poly molecular adducts, like in this study, we have chosen to describe in the main text the enthalpy-profiles. The corresponding free-enthalpy profiles leading to the same conclusions are reported in the supplementary information (SI-Figures S42-S44).

[15] a) A. P. M. Robertson, E. M. Leitao, I. Manners, J. Am. Chem. Soc. 2011, 133, 19322-19325; b) E. M. Leitao, N. E. Stubbs, A. P. Robertson, H. Helten, R. J. Cox, G. C. Lloyd-Jones, I. Manners, J. Am. Chem. Soc. 2012, 134, 16805-16816.

[16] I. P. Oliveri, G. Maccarrone, S. Di Bella, J. Ors. Chem. 2011, 76, 8879-8884. 


\section{FULL PAPER}

Uncatalyzed Formation of Polyaminoboranes from Diisopropylaminoborane and Primary Amines: a Kinetically Controlled Polymerization Reaction

Adv. Synth. Catal. Year, Volume, Page - Page

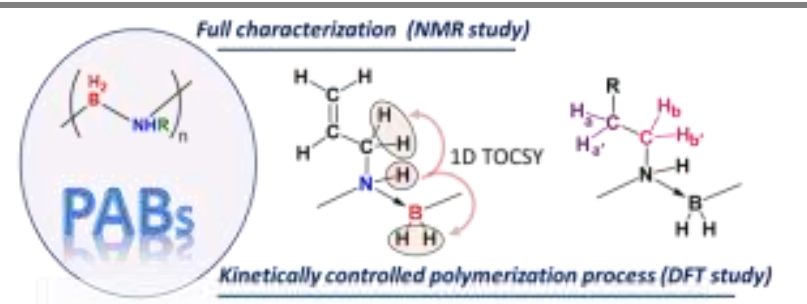

Marc Devillard, Carlos Antonio De Albuquerque

Pinheiro, Elsa Caytan, Claire Roiland, Chiara

Dinoi, Iker Del Rosal, and Gilles Alcaraz*

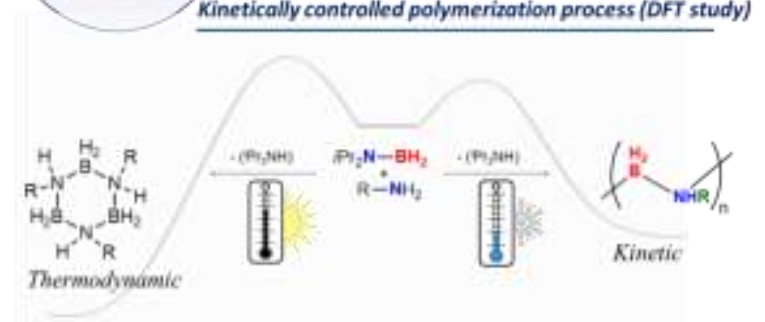

